\title{
Management of COVID-19 Patient in Cardiac Surgery with Cardiopulmonary Bypass
}

\author{
Alfred Ibrahimi ${ }^{*}$, Saimir Kuci ${ }^{1}$, Ervin Bejko ${ }^{1}$, Stavri Llazo $^{1}$, Esmerilda Bulku${ }^{1}$, Jonela Burimi ${ }^{1}$, \\ Marsela Goga ${ }^{1}$, Selman Dumani ${ }^{2}$, Ermal Likaj ${ }^{1}$, Jacob Zeitani ${ }^{3}$, Edvin Prifti ${ }^{2}$
}

Received: 28 December 2020 / Accepted: 11 January 2021 / Published online: 20 January 2021

(C) The Author(s) 2021. This article is published with open access at https://journal.astes.org.al

\begin{abstract}
Introduction: The diagnosis of COVID-19 is quite challenging due to the inconsistent correlation between laboratory findings, radiological imaging, and the clinical picture and contact history of the patient. The patients who underwent cardiac surgery with cardiopulmonary bypass (CPB) face double risk because CBP triggers an intense inflammatory response and the leading cause of mortality in COVID-19 patients is "cytokine storm". In our institution 15 confirmed cases operated on with open-heart surgery. 9 cases isolated $\mathrm{CABG}, 4$ cases valvular combined with $\mathrm{CABG}$, and 1 valvular disease.

Materials and method: All patients undergoing elective or urgent cardiac surgery at "Mother Theresa" 's Hospital from 11 March to 30 November 2020 were included in this study. Patients diagnosed with COVID-19 infection via positive throat swab taken due to clinical suspicion postoperatively were reviewed. Patients characteristics, type of intervention, date of COVID-19 diagnosis.

Results: 9 patients (72\%) normal recovery, no respiratory failure, only 3-5 days of fever (max 39,4). 3 of them a moderate respiratory failure. 3 patients with severe respiratory failure. Only 3 deaths $(26,6 \%)$.

Recommendation: It's important to a preoperative screening for COVID-19 patients. The outcome of cardiac surgical patients who contracted COVID-19 infection perioperatively is extremely poor. Aggressive respiratory assistance (early intubation), high doses of corticosteroids, and anticoagulation, better results.

Key words. COVID-19. Cardiac surgery. Impact, Cytokine storm
\end{abstract}

\section{Introduction:}

First confirmed case of coronary virus SARS-CoV -2 in Albania was identified in 8 march 2020. After first death case in eleven march, Albanian government, like in any part of the world. took a restrictive measure, to reduce the number of the contaminated people. Another important measure, in order to eliminate the possibility of infection of health personnel, and to focus attention on solving unknown problems from this new disease, was the cessation of

Original article, no submission or publication in advance or in parallel

* Corresponding author: Alfred IBRAHIMI MD, Ph.D.

凹alfredibrahimi@hotmail.com

1 Anesthesia and ICU Service, University Hospital Centre "Mother Theresa", Tirana, ALBANIA

2 Cardiac Surgery Service, University Hospital Centre "Mother Theresa", Tirana, ALBANIA

3 Cardiac Surgery Service "German International" -Tirana, ALBANIA elective operations. In this way vacancies could be provided in intensive care, so important for patients with COVID-19. These statistics show that the greatest possibility for contamination of health personnel in in ICU and in ward, where there is direct contact with infected patients.

\section{Impact of postponing cardiac surgery.}

Postponing heart surgery will increase the risks of morbidity and mortality of the patients in the waiting list. A PubMed search of original, observational studies reporting complications while awaiting $\mathrm{CABG}$ or percutaneous coronary intervention (PCI) revealed that mortality, nonfatal myocardial infarction, and urgent revascularization are higher in patients with severe angina and left ventricular dysfunction [1]. The type of surgery should also be considered to determine the level of priority for the planned cardiac interventions. A prospective cohort analysis of death rates while waiting for cardiac surgery revealed that patients waiting for valve surgery have a higher risk of mortality than patients waiting for isolated CABG [2]. Postponing elective surgery has an important effect in early postoperative mortality in our center. During three months (March- June), morbidity and postoperative complication were increased, using intra-aortic balloon pump (IABP), and continuous 
renal replacement therapy (CRRT). The mortality was tripled compared with the same time of the last year.

\section{Risk for health care workers.}

To perform a cardiosurgical intervention necessitates a considerable number of medical staff, starting from cardiac surgeons, anesthetists with their assistants, nurse, and perfusion physician. This level of traffic is a risk factor for surgical site infection and human errors [3]. To reduce the spread of the virus and the contamination of the health personnel and the patient admitted for intervention a series of measures had been taken, starting use of PPE mask, hand sanitizer, apneic intubation suggested by Peng and Hota during induction of anesthesia, and closed respiratory circuits, with special incorporated filter [4] A retrospective multicenter clinical study comprising 37 patients (5 confirmed and 32 suspected COVID-19) scheduled for emergency procedures, including cardiac procedures, showed that strict adherence to the guidelines of infection control could effectively decrease cross-infection in the operating room [5]. Despite these restrictive measures, 90 $\%$ of works in ICU, $60 \%$ in ward and only $10 \%$ of nursing staff in operating room, were infected with this virus

\section{Materials and methods.}

All patients undergoing elective or urgent cardiac surgery at "Mother Theresa" 's Hospital from 11 March to 30 November 2020 were included in this study. Patients diagnosed with COVID-19 infection via positive throat swab taken due to clinical suspicion postoperatively were reviewed. Patients characteristics, type of intervention, date of COVID-19 diagnosis.

\section{Results.}

During the study period in our institution were performed 556 operation. 15 of them resulted positive of covid-19 in postoperative period. Mean age was 57,6 (49-72) years. Only three of them were female. Three operation were performed in urgent situation and 13 were hospitalized days before. Patients demographic data are presented in table 1.

Nine $(n=9)$ procedures were coronary artery bypass graft $(\mathrm{CABG})$. Aortic valve replacement $(\mathrm{n}=1)$, mitral valve replacement $(n=1)$. Bivalvular replacement $(n=1)$, and 2 cases of combined surgery (CABG +Valvular replacement). Preoperative hospital stay was $6.2 \pm 5$ day, and time of diagnosis was $6,9 \pm 4$ day postoperatively. 14 patients had a pyrexia immediately after surgery and 11 radiology changes. 12 patients developed a satisfactory postoperative course, Mortality was 26,6\%.

\section{Discussion.}

COVID-19 is a very serios respiratory disease, and in a patient with comorbidities leads to severe respiratory failure, and in death due to multi organ failure (MOF). COVID-19 infection following cardiac surgery is associated

Table 1 Patients characteristics diagnosed of COVID-19

\begin{tabular}{|c|c|c|c|c|c|c|}
\hline Patient & $\mathbf{M} / \mathbf{F}$ & Age & $\mathbf{E} / \mathbf{U}$ & Operation & Bypass/Min & Preoperative Day \\
\hline 1 & $\mathrm{~F}$ & 72 & $\mathbf{E}$ & $\begin{array}{l}\mathrm{MVR}+ \\
\text { CABG REDU }\end{array}$ & 95 & 10 \\
\hline 2 & $\mathbf{M}$ & 56 & $\mathbf{E}$ & CABG & 77 & 8 \\
\hline 3 & $\mathbf{M}$ & 62 & $\mathbf{E}$ & CABG & 56 & 5 \\
\hline 4 & $\mathbf{M}$ & 58 & $\mathbf{E}$ & CABG & 63 & 7 \\
\hline 5 & $\mathbf{M}$ & 52 & $\mathbf{E}$ & CABG & 68 & 5 \\
\hline 6 & $\mathbf{M}$ & 53 & $\mathrm{E}$ & MVR+AVR & 125 & 6 \\
\hline 7 & $\mathbf{M}$ & 66 & $\mathrm{E}$ & CABG & 83 & 10 \\
\hline 8 & $\mathbf{M}$ & 49 & $\mathbf{E}$ & CABG & 74 & 7 \\
\hline 9 & $\mathbf{M}$ & 55 & $\mathbf{E}$ & AVR & 70 & 9 \\
\hline 10 & $\mathbf{M}$ & 73 & $\mathbf{E}$ & $\mathrm{MVR}+\mathrm{CABG}$ & 144 & 8 \\
\hline 11 & $\mathbf{M}$ & 72 & $\mathbf{E}$ & $\mathrm{AVR}+\mathrm{CABG}$ & 133 & 3 \\
\hline 12 & M & 57 & $\mathbf{U}$ & CABG & 84 & 2 \\
\hline 13 & $\mathrm{~F}$ & 71 & $\mathbf{U}$ & CABG & 37 & 1 \\
\hline 14 & M & 59 & $\mathbf{U}$ & MVR & 84 & 2 \\
\hline 15 & $\mathbf{M}$ & 79 & $\mathbf{E}$ & CABG & 105 & 10 \\
\hline
\end{tabular}


Table 2 - Clinical features on the day of COVID-19 diagnosis

\begin{tabular}{|c|c|c|c|c|c|c|}
\hline Patient & $\begin{array}{l}\text { Day of } \\
\text { CoviD } \\
\text { diagnosis }\end{array}$ & Outcome & Pyrexia & $\begin{array}{l}\text { Raised } \\
\text { WCC }\end{array}$ & $\begin{array}{l}\text { Raised } \\
\text { CRP }\end{array}$ & $\begin{array}{l}\text { Radiology } \\
\text { changes }\end{array}$ \\
\hline 1 & 3 & Died & 39.2 & No & Yes & Yes \\
\hline 2 & 8 & Home & 38.5 & Yes & Yes & No \\
\hline 3 & 5 & Home & 38.5 & No & Yes & No \\
\hline 4 & 5 & Home & 39.1 & yes & Yes & yes \\
\hline 5 & 5 & Home & 38,5 & yes & Yes & yes \\
\hline 6 & 6 & Died & 39.2 & No & Yes & yes \\
\hline 7 & 10 & Home & 38,5 & Yes & Yes & yes \\
\hline 8 & 7 & Died & 38,4 & Yes & Yes & yes \\
\hline 9 & 9 & Home & 37.8 & No & Yes & no \\
\hline 10 & 8 & $\begin{array}{l}\text { Home, } \\
\text { died }\end{array}$ & 39.5 & No & Yes & yes \\
\hline 11 & 3 & Home & 36.7 & No & Yes & Yes \\
\hline 12 & 4 & Home & 38.1 & No & Yes & Yes \\
\hline 13 & 7 & Home & 36.5 & No & No & Yes \\
\hline 14 & 14 & Home & 38.6 & No & No & No \\
\hline 15 & 10 & Home & $?$ & Yes & Yes & Yes \\
\hline
\end{tabular}

COVID-19: coronavirus 2019; CRP: c-reactive protein; WCC: white cell count.

with very poor outcomes and in our series of 15 patients, a mortality of $26.6 \%$, but this mortality is not real, because the firs patient diagnosed postoperatively with COVID-19, after aggressive assistance in Cardiac surgery ICU ( 8 days in mechanical ventilation, CRRT) was transferred in infective disease hospital, died after 3 days. The second patient died, after acute postoperative tamponade, and the third died after he was discharged from hospital. In a similar study of nine patient the mortality was much higher $44 \%$ [6].

Why is so high the mortality in cardiac patients? Is the use of extracorporeal circulation?

Cardiac surgery involves a unique concern in contrast to other elective surgeries, which is the use of cardiopulmonary bypass (CPB). The exposure of blood to the non-endothelial surfaces during $\mathrm{CPB}$ triggers an inflammatory response by activation of coagulation pathways, complement system, and increasing the level of tumor necrosis factor a (TNF-a) and interleukin 10 (IL-10) [7]. There is evidence attributed the cause of ARDS in COVID-19 to cytokine storm syndrome, especially that high levels of proinflammatory cytokines (TNF-a and IL10) were measured in patients with COVID- 19 and this has also been correlated with the severity of the disease [8] It is unclear as regards the contribution of cardiopulmonary bypass, postoperative ventilation and obvious cardiac comorbidities to the outcomes in these patients.

All, our patients have been in contact with a virus, before or during hospital stay before surgery. However, the clinical manifestations only appeared in the postoperative period. There was no established COVID -19 screening protocol preoperatively and postoperatively during the period in which these patients were operated on. Gradually we become informed from COVID hospitals for high morbidity and mortality of this disease, and our experience also increased. We have instituted local protocols aimed at thorough screening of all patients before and on arrival in our unit to ensure that we do not admit or operate on anyone with the virus and isolating patients with unknown COVID-19 status To illustrate our work, we are presenting a special case of postoperative COVID-19.

Case; A woman 72 years old, was scheduled for elective operation. She was suffering for mitral regurgitation and aortic stenosis, pulmonary hypertension $(55 \mathrm{mmHg})$, low ejection fraction FE-35\%, diabetes mellitus with insulin, and impaired renal function. Three years before it was implanted a permanent pacemaker DDD-R, after she came to hospital in cardiogenic shock. After preoperative preparation the patient was send in operation room. Operation consisted in both replacement of aortic and mitral valve with biologic prothesis. Cross clamp time $92 \mathrm{~min}$ and by pass time 120 min. Weaning from cardiopulmonary bypass with support of inotropic drugs. Postoperative period in firs 3 days went relatively well, in fifth days shorten of breath and reduction of oxygen saturation (O2Sat) to $85 \%$. Diuretic therapy doesn't improve the situation, so after the thorax CT scan (fig 1), COVID-19 was suspected. PCR-test resulted also positive. Her daughter resulted positive, in the USA, after leaving Albania days before her mother. 
Figure 1 Evolution of radiologic images of COVID-19 in acute phase.

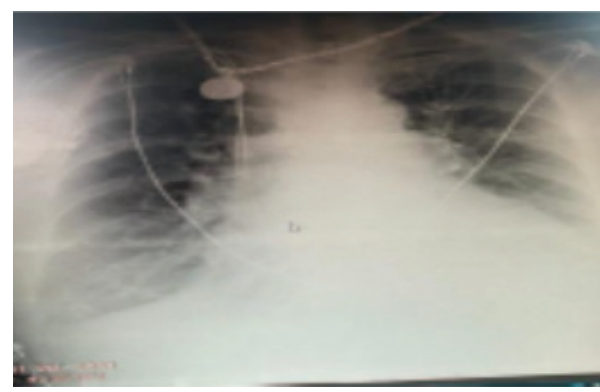

Before Operation

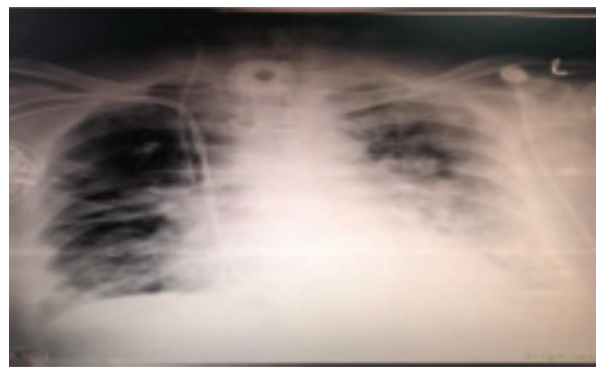

7 days after Operation

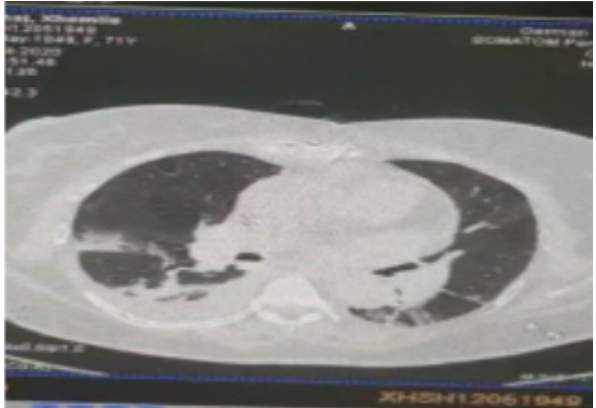

Chest CT-scanner 10 days after Operation

Situation became much worse, and mechanical ventilation after intubation was started. The patient was ventilated with Acute lung Injury set up of the ventilator with low tidal volume and high PEEP ( $\max 8 \mathrm{mmHg}$ ). Antibiotic therapy, initially with Piperacillin + Tazobactam, and amikacin, because klebsiella pneumonia was explored in sputum. Heparin iv was started and a PTT was maintained at value $70-90 \mathrm{sec}$. High doses of methylprednisolone (500 $\mathrm{mg}$ in first two days and half dose in 2 other consecutive days. In fifth day, under protective measures, percutaneous tracheostomy was performed. Piperacillin was changed with imipenem, and metronidazole was started too. Gradually laboratory data came towards improvement. (Tab.3)

Table 3 Evolution of laboratory data.

\begin{tabular}{|l|l|l|l|l|l|l|l|}
\hline Lab value & 9.10 .2020 & 11.10 .2020 & 21.10 .2020 & 25.10 .2020 & 29.10 .2020 & 2.11 .2020 & 6.11 .2020 \\
\hline Leukocytes & 9.41 & 16.684 .7 & 3.92 & 11.95 & 7.57 & 4.75 & 8.09 \\
\hline Lymphocytes & 12.7 & 4.7 & 6.9 & 2.4 & 4.8 & 6.9 & 7.1 \\
\hline D-dimer & & & & & & & \\
\hline
\end{tabular}


Respiratory parameters began to improve day by day and $\mathrm{PaO} 2 / \mathrm{FiO} 2<200$. Twenty days after operation, the patient was in spontaneous respiration, with a little support of oxygen. Despite non correlation between radiologic imaging (Fig 2) and blood oxygen improvement, health situation became better. Tracheostomy was removed and thirty-five days after operation the patients was discharge from hospital in stable condition.

\section{Figure 2 Evolution of radiologic images of COVID-19.}

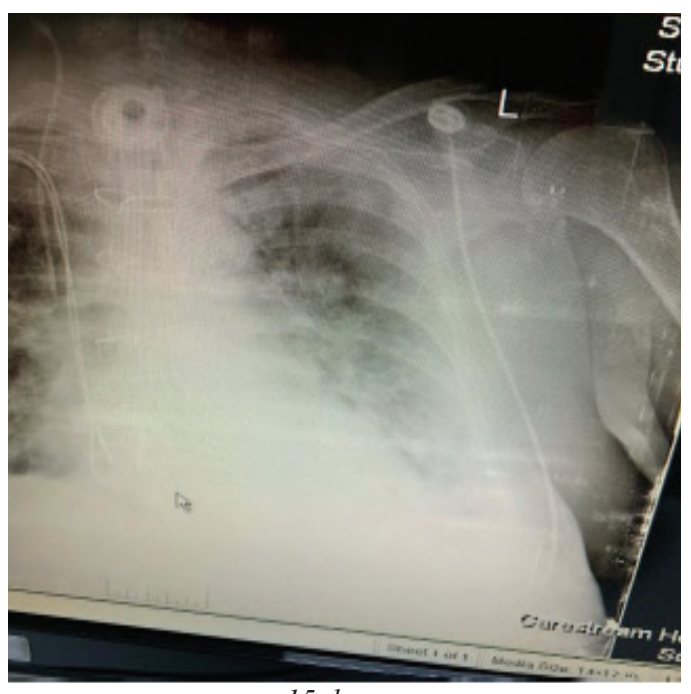

15 days

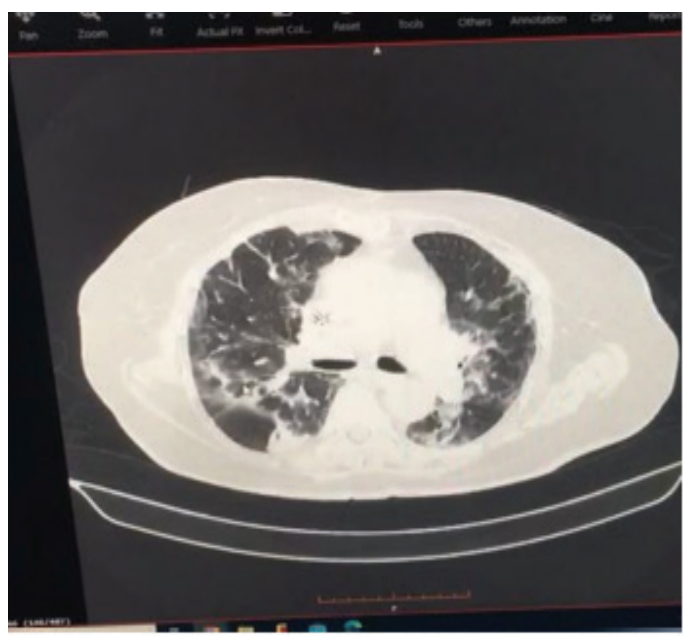

30 days

\section{Conclusion}

Treating a COVID-19 patient after cardiac surgery is very challenging. After postoperative COVID-19 diagnosis, should be prepared for worst scenario. Should be implanted rigorous protocols aimed at maintaining a COVID-19 protective environment to minimize additional lifethreatening complications related to this virus infection. In case of infection, aggressive, respiratory assistance, high doses of corticosteroids, anticoagulation better results.
COI Statement: This paper has not been submitted in parallel. It has not been presented fully or partially at a meeting or podium or congress. It has not been published nor submitted for consideration beforehand.

This research received no specific grant from any funding agency in the public, commercial, or non-profit sectors. There are no relevant or minor financial relationships from authors, their relatives or next of kin with external companies.

Disclosure: The authors declared no conflict of interest. No funding was received for this study.

Acknowledgement: We would like to thank medical staff of Department of Anaesthesiology and Reanimation, at University Hospital Centre "Mother Theresa", Tirana, ALBANIA.

\section{References}

1. Head SJ, da Costa BR, Beumer B, et al. Adverse events while awaiting myocardial revascularization: a systematic review and meta- analysis. European Journal of Cardio-Thoracic Surgery 2017 Aug 1;52(2):206e17

2. Morgan CD, Sykora K, Naylor CD. Steering Committee of the Cardiac Care Network of Ontario. Analysis of deaths while waiting for cardiac surgery among 29293 consecutive patients in Ontario, Canada. Heart 1998 Apr 1;79(4):345e9

3. Young RS, O'Regan DJ. Cardiac surgical theatre traffic: time for traffic calming measures? Interactive cardiovascular and thoracic surgery 2010 Apr 1;10(4):526e9.

4. Editorial Br J Anaesth 2020 May;124(5):497-501. doi: 10.1016/j.bja.2020.02.008. Epub 2020 Feb 27. Outbreak of a new coronavirus: what anaesthetists should know Philip W H Peng ${ }^{1}$, Pak- Leung $\mathrm{Ho}^{2}$, Susy S Hota ${ }^{3}$ Affiliations expand PMID: 32115186 PMCID: PMC7124191DOI: 10.1016 jj.bja.2020.02.008 Free PMC article

5. Zhao S, Ling K, Yan $\mathrm{H}$, et al. Anesthetic management of patients with suspected 2019 novel coronavirus infection during emergency procedures. Journal of Cardiothoracic and Vascular Anesthesia 2020 Feb 28.

6. Outcomes of patients diagnosed with COVID-19 in the early postoperative period following cardiac surgery Martin T. Yates, Damian Balmforth, Ana Lopez-Marco, Rakesh Uppal and Aung Y. OoInteractive CardioVascular and Thoracic

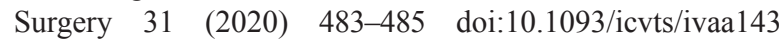
Advance Access publication 13 August 2020

7. Gaudriot B, Uhel F, Gregoire M, et al. Immune dysfunction after cardiac surgery with cardiopulmonary bypass: beneficial effects of maintaining mechanical ventilation. Shock 2015 Sep $1 ; 44(3): 228 \mathrm{e} 33$

8. Chen C, Zhang XR, Ju ZY, et al. Advances in the research of cytokine storm mechanism induced by Corona Virus Disease 2019 and the corresponding immunotherapies. Zhonghua shao shang Za zhi $1 / 4$ Zhonghua shaoshang zazhi $1 / 4$ Chin Journal of Burns 2020 Mar 1;36: E005 